\title{
Use and Effect of Vasopressors after Pediatric Traumatic Brain Injury
}

\author{
Jane L. Di Gennaro ${ }^{a}$ Christopher D. Mack ${ }^{d}$ Amin Malakouti $^{b}$ \\ Jerry J. Zimmerman ${ }^{a}$ William Armstead $^{\text {e Monica S. Vavilala }}{ }^{\text {a-d }}$ \\ Departments of a Pediatrics, ${ }^{b}$ Anesthesiology and Pain Medicine and ${ }^{c}$ Neurological Surgery, \\ University of Washington, and ${ }^{\mathrm{d}}$ Harborview Injury Prevention and Research Center, Seattle, Wash., and \\ eDepartment of Anesthesiology, University of Pennsylvania, Philadelphia, Pa., USA
}

\section{Key Words}

Hypotension $\cdot$ Head injury $\cdot$ Children $\cdot$ Vasopressor

\begin{abstract}
Background: Vasopressors are commonly used to increase mean arterial blood pressure (MAP) and cerebral perfusion pressure (CPP) after traumatic brain injury (TBI), but there are few data comparing vasopressor effectiveness after pediatric TBI. Objective: To determine which vasopressor is most effective at increasing MAP and CPP in children with moderate-to-severe TBI. Methods: After institutional review board approval, we performed a retrospective cohort study of children $0-17$ years old admitted to a level 1 trauma center (Harborview Medical Center, Seattle, Wash., USA) between 2002 and 2007 with moderate-to-severe TBI who received a vasopressor to increase blood pressure. Baseline demographic and physiologic characteristics and hourly physiologic monitoring for $3 \mathrm{~h}$ after having started a vasopressor were abstracted. We evaluated differences in MAP and CPP at $3 \mathrm{~h}$ after initiation of therapy between phenylephrine, dopamine and norepinephrine among patients who did not require a second vasopressor during this time. Multivariate linear regression was used to adjust for age, gender, injury severity score and baseline MAP or CPP and to cluster by subject. Results: Eighty-two patients contributed data to the en-
\end{abstract}

tire dataset. The most common initial medication was phenylephrine for 47 (57\%). Patients receiving phenylephrine and norepinephrine tended to be older than those receiving dopamine and epinephrine. Thirteen (16\%) of the patients received a second vasopressor during the first $3 \mathrm{~h}$ of treatment and were thus not included in the regression analyses; these patients received more fluid resuscitation and exhibited higher in-hospital mortality (77 vs. $32 \% ; p=0.004)$ compared to patients receiving a single vasopressor. The norepinephrine group exhibited a $5 \mathrm{~mm} \mathrm{Hg}$ higher MAP $(95 \% \mathrm{Cl}:-4$ to $13 ; \mathrm{p}=0.31)$ and a $12 \mathrm{~mm} \mathrm{Hg}$ higher CPP $(95 \% \mathrm{Cl}:-2$ to 26 ; $\mathrm{p}=0.10$ ) than the phenylephrine group, and a $5 \mathrm{~mm} \mathrm{Hg}$ higher MAP (95\% Cl: -4 to $15 ; p=0.27)$ and a $10 \mathrm{~mm} \mathrm{Hg}$ higher CPP (95\% Cl: -5 to $25 ; p=0.18)$ than the dopamine group. However, in post hoc analysis, after adjusting for time to start of vasopressor, hypertonic saline and pentobarbital, the effect on MAP was lost, but the CPP was $8 \mathrm{~mm} \mathrm{Hg}$ higher $(95 \%$ $\mathrm{Cl}:-10$ to $25 ; \mathrm{p}=0.39)$ than in the phenylephrine group, and $5 \mathrm{~mm} \mathrm{Hg}$ higher ( $95 \% \mathrm{Cl}:-14$ to $24 ; \mathrm{p}=0.59$ ) than in the dopamine group. Conclusions: Vasopressor use varied by age. While there was no statistically significant difference in MAP or CPP between vasopressor groups, norepinephrine was associated with a clinically relevant higher CPP and lower intracranial pressure at $3 \mathrm{~h}$ after start of vasopressor therapy compared to the other vasopressors examined.

Copyright @ 2010 S. Karger AG, Basel

Monica S. Vavilala, MD

Department of Anesthesiology and Pediatrics

Harborview Medical Center

325 Ninth Avenue, Box 359724, Seattle, WA 98104 (USA)

Tel. +1 206744 3210, Fax +1 206744 8090, E-Mail vavilala@ u.washington.edu 


\section{Introduction}

Traumatic brain injury (TBI) is the leading cause of death among injured children $[1,2]$. While the ultimate means for decreasing poor outcome after TBI is primary trauma prevention, minimizing or eliminating subsequent brain injury from secondary insults such as hypotension is also of paramount importance. Yet there is limited information regarding how to best treat hypotension after pediatric TBI.

Hypotension and low cerebral perfusion pressure $[\mathrm{CPP}=$ mean arterial blood pressure $(\mathrm{MAP})$ - intracranial pressure (ICP)] are associated with poor outcomes after TBI in children [3-12]. Consequently, although it remains unclear whether targeting a specific CPP will lead to improved clinical outcomes, current 2003 Pediatric Guidelines recommend preventing or rapidly treating hypotension and maintaining CPP above $40 \mathrm{~mm} \mathrm{Hg}$ in children, noting that an age-related continuum for the optimal CPP likely lies between 40 and $65 \mathrm{~mm} \mathrm{Hg}$ [13]. Higher CPP values are possibly necessary for older children whose CPP needs may approximate those of adults, with adult guidelines recommending a CPP between 50 and $70 \mathrm{~mm} \mathrm{Hg}$ [14]. Despite these current therapeutic targets, guidelines regarding how this should be achieved primarily describe therapies to lower ICP $[13,14]$. Given that CPP can be low on the basis of elevated ICP or inadequate blood pressure, in addition to decreasing ICP, one commonly employed strategy to increase CPP is to use inotropes and or vasopressors to increase MAP. Yet there are no studies describing vasopressor use or comparing vasopressor effectiveness in the setting of pediatric TBI. Given this gap in knowledge, we aimed to describe current institutional vasopressor use and evaluate vasopressor effectiveness in increasing MAP and CPP after pediatric TBI.

\section{Patients and Methods}

\section{Study Design}

After institutional review board approval, we performed a retrospective cohort study of children admitted to Harborview Medical Center (Seattle, Wash., USA), a regional pediatric level 1 trauma center, from 2002 to 2007.

\section{Study Population}

Children 0-17 years old admitted to the study center with moderate-to-severe TBI who received therapy with 1 or more vasopressors (phenylephrine, norepinephrine, dopamine, epinephrine or vasopressin) for at least $3 \mathrm{~h}$ to explicitly improve MAP were considered eligible. An admission Glasgow Coma Scale (GCS) score of $\leq 12$ or head Abbreviated Injury Scale (AIS) score of $\geq 3$ and an ICD-9 code indicating a TBI (800-801.9, 803-804.9, 850854.1 or 959.01 ) defined moderate-to-severe TBI. We included several measures to assess severity of injury: GCS score on admission to the intensive care unit (ICU), head AIS score, Injury Severity Score (ISS), in-hospital mortality, length of hospital stay (LOS) for survivors, and polytrauma. Patients with polytrauma (any extracranial injury) were included. We excluded patients who were in the operating room during the 3 -hour observation period, patients who received vasopressin for diabetes insipidus as their only vasopressor, and patients who had received a vasopressor prior to arrival at the study hospital or otherwise lacked documentation of paired baseline and 3-hour vital signs.

\section{Data Sources and Measures}

We linked Harborview Medical Center trauma registry data with hospital billing data to identify children with moderate-tosevere TBI who were treated with a vasopressor. As billing data were not electronically available for periods earlier than fiscal year 2003, we performed a manual search for all patients identified by the trauma registry for 2002 . We also included available data from patients who received vasopressors for another study on pediatric TBI where hemodynamic and vasopressor data were available [15].

Medical records were abstracted to obtain demographic and physiologic parameters, volumes of blood products received, fluid balance, concurrent medications and relevant therapies as well as other diagnoses. In-hospital mortality, LOS, ISS and head AIS score were obtained from the trauma registry.

During the study period, there was no standard protocol regarding vasopressor use for blood pressure management (MAP or $\mathrm{CPP}$ ) for pediatric TBI at this institution. In general, a tiered approach to treatment of intracranial hypertension was utilized, including positional maneuvers (head of bed to $30^{\circ}$, neck in midline), mechanical ventilation, sedation, blood pressure management and osmolar therapies (mannitol and/or hypertonic saline). Neuromuscular blockers were typically only used in cases of refractory intracranial hypertension. Routine hyperventilation practice decreased over the study years, and dextrose-containing maintenance fluids were not routinely used during the first $24 \mathrm{~h}$ during the latter study years. Hypothermia was not routinely used during any of the study years. Additional maneuvers, including rescue therapy with hypothermia and decompressive craniectomy, were performed in select cases of intractable intracranial hypertension.

The primary outcomes were (1) initial vasopressor choice, and (2) MAP at $3 \mathrm{~h}$ after initiation of a single vasopressor with adjustment for baseline MAP. When data were available, we also examined the effect of drug choice on CPP. To identify the baseline MAP for each patient, we used the lowest recorded MAP in the hour prior to initiation of a vasopressor. As MAP was typically recorded hourly in the medical record, but a vasopressor could be initiated at any time, the 3-hour MAP value was the value closest to $3 \mathrm{~h}$ after the start of treatment (i.e. from 2.5 to $3.5 \mathrm{~h}$ ). Most patients had a combination of invasive and noninvasive blood pressure measurements. For all patients except one, the baseline and 3-hour blood pressure measurements were measured in a similar fashion (i.e. both noninvasive or both invasive). When both invasive and noninvasive blood pressure measurements were available for both baseline and $3 \mathrm{~h}$, we used the noninvasive measurement 
as this measurement more often guided clinical nursing care (local practice). For the 1 patient who had baseline and 3-hour measurements by discordant techniques, the invasive and noninvasive measurements were within $2 \mathrm{~mm} \mathrm{Hg}$ of each other at other times during the period of observation. We also recorded how many patients in each exposure category received a second vasopressor or were switched to a different vasopressor during the first $3 \mathrm{~h}$ of therapy.

\section{Statistical Analysis}

Basic descriptive statistics by vasopressor category are presented as medians and interquartile ranges (IQR), or minimum and maximum, given low patient numbers and concern for skewing of the data and proportions for binary variables. We assessed these statistics for: (1) the study population as a whole including patients receiving a single agent and those on multiple agents, and (2) the subpopulations of those patients receiving only 1 vasopressor in the first $3 \mathrm{~h}$ with available data for inclusion in the regression analyses for MAP and CPP. Descriptive statistics were also calculated to characterize patients receiving a single vasopressor versus multiple vasopressors in the first $3 \mathrm{~h}$, using the MannWhitney $U$ test for continuous data and Fisher's exact test for binary data to compare characteristics.

Crude descriptive data regarding baseline and 3-hour vital signs (MAP, CPP, ICP and heart rate) by vasopressor category in patients who received a single vasopressor are presented as median differences in vital signs at $3 \mathrm{~h}$ of therapy compared to baseline; only patients with both baseline and 3-hour measurements were included. Baseline MAP between the vasopressor groups was compared using linear regression with robust standard errors adjusting for age.

To examine the effect of vasopressors on MAP, we used multivariate linear regression to assess patients who did not require addition of a second drug during the first $3 \mathrm{~h}$ after initiation of treatment. We chose to evaluate only patients receiving monotherapy in the regression analyses in order to evaluate that single vasoactive agent rather than try to define/evaluate each different combination of vasoactive agents or attribute the response from a combination of agents to the first agent. The independent variable was drug category, which was treated as a dummy variable. The reference drug group was phenylephrine as this was the group with the greatest number of patients. The dependent variable was the mean of MAP at $3 \mathrm{~h}$, and we controlled for the baseline values in an analysis of covariance model (unadjusted analysis). In addition to controlling for baseline MAP, in the adjusted model we decided a priori to adjust for age, gender and ISS as these were felt to be potential confounders. We used robust standard error estimates in order to allow for unequal variances across groups, and clustered by subject, given the longitudinal nature of the measurements. The estimates from the regression model were interpreted as the difference in mean MAP at $3 \mathrm{~h}$ for each of these vasopressor categories compared to the reference category (phenylephrine) adjusted for age, gender, ISS and baseline value. We also analyzed CPP, ICP and heart rate, utilizing multivariate linear regression in similar models as that for MAP.

We compared mean percent increase in MAP between 2 age groups: the youngest ( $0-5$ years) and oldest (14-17 years) age groups for each vasopressor category in those patients receiving a single agent during the first $3 \mathrm{~h}$ using two-sample $\mathrm{t}$ tests with unequal variances. We also compared the median value of MAP during the $3 \mathrm{~h}$ prior to vasopressor start to the minimum value during the hour prior to vasopressor start as well as the 3-hour MAP value to the median MAP over the $3 \mathrm{~h}$ after starting a vasopressor, using paired t tests.

\section{Results}

Descriptive Statistics: All Patients ( $n=82$, Patients

Receiving Single and Multiple Vasoactive Agents)

We identified 82 patients who met the study inclusion criteria (fig. 1). There was a U-shaped trend to the age distribution of the patients, with most patients being at the older or younger end of the spectrum. The most common initial drug used was phenylephrine (57\%), followed by dopamine (29\%). A large proportion of patients in all vasopressor categories had polytrauma (33-88\%); extracranial injuries in those patients with polytrauma consisted of orthopedic $(80 \%)$, abdominal $(39 \%)$, thoracic (59\%) and multiple extracranial sites (59\%). The descriptive statistics indicated some key differences between initial vasopressor groups (table 1). Patients receiving phenylephrine and norepinephrine were older than those receiving dopamine and epinephrine. The ISS and the proportion of patients with polytrauma were highest in the norepinephrine group, but these patients had the lowest in-hospital mortality. Time to vasopressor start was longer in the norepinephrine group. Hypertonic saline was used more frequently in the norepinephrine group, and pentobarbital in the dopamine group.

\section{Single versus Multiple Vasopressors}

Most patients (69/82) were treated with a single vasopressor during the first $3 \mathrm{~h}$ after start of vasopressor therapy. The multiple vasopressor group had a lower median GCS score $(\mathrm{p}=0.057)$ and higher in-hospital mortality (77 vs. $32 \% ; p=0.004)$. They also had a greater positive fluid balance $(\mathrm{p}=0.036)$ and shorter time to pressor start $(\mathrm{p}=0.006)$, and they less often received propofol, hypertonic saline and mannitol (table 2).

\section{Descriptive Statistics: Patients Receiving a Single \\ Vasopressor $(n=69)$}

Patients receiving a single vasopressor had similar characteristics to the entire study population described above, except for slightly lower in-hospital mortality in the dopamine and norepinephrine groups (table 3). However, in the group with complete CPP measurements ( $\mathrm{n}=$ 48), several differences from the characteristics of the entire study population were observed (table 3 ). There was 
Fig. 1. Flowchart for screening and inclusion of patients. 82 patients received vasopressors, 69 of whom received single-vasopressor therapy in the first $3 \mathrm{~h}$.

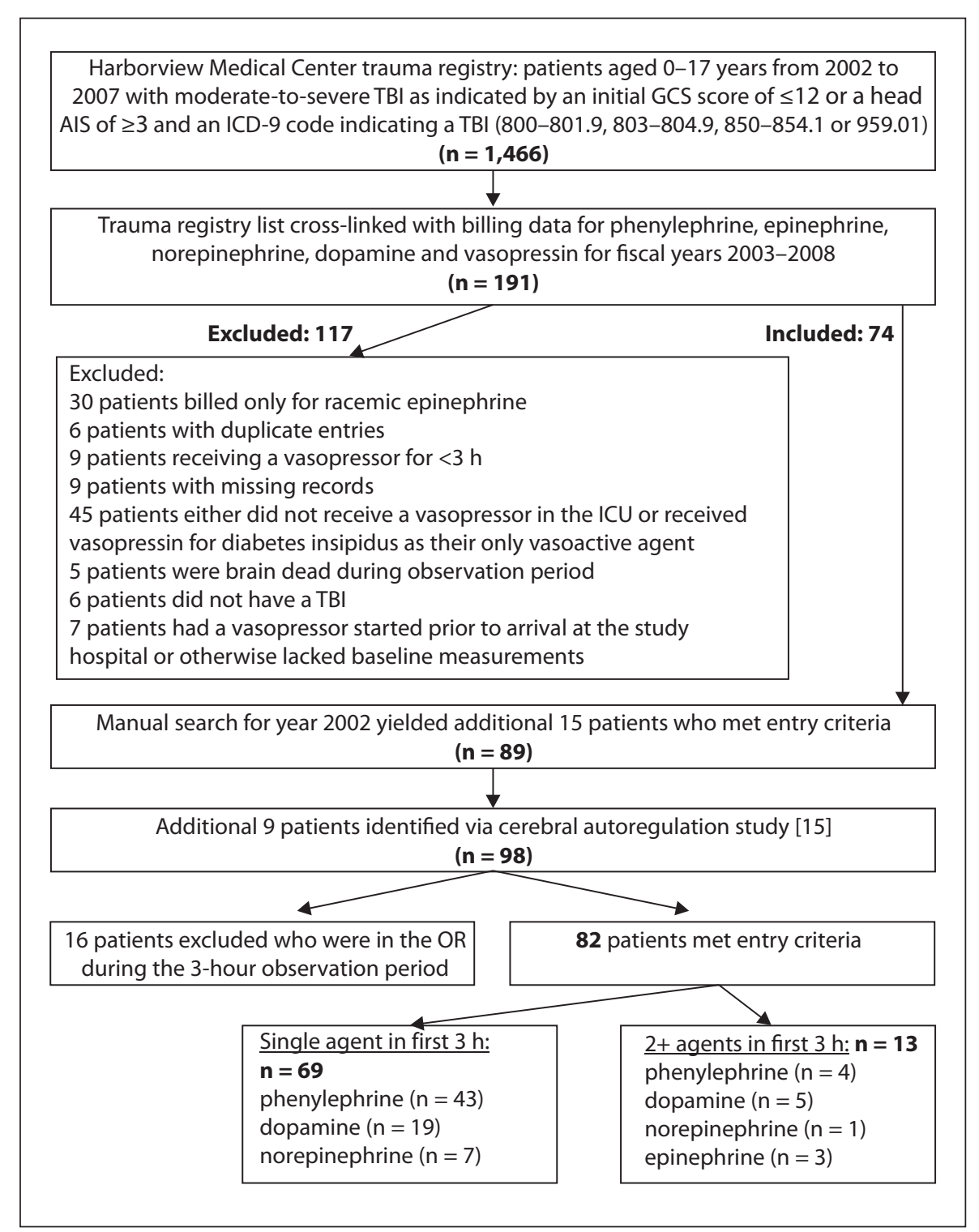

greater propofol and mannitol use in the norepinephrine group. The dopamine group had a longer time to vasopressor start, lower fluid balance, decreased in-hospital mortality, increased polytrauma and greater pentobarbital use.

\section{Regression Analyses of Patients Who Received 1 \\ Vasopressor}

Crude vital sign data (MAP, CPP, ICP and heart rate), presented as median differences in vital signs at $3 \mathrm{~h}$ of therapy compared to baseline, are provided as a clinical frame of reference to provide a context for interpreting the regression analyses (table 4). Baseline MAP, adjusted for age, between the 3 vasopressor groups was statistically different $(\mathrm{p}=0.02)$; patients who received phenylephrine had the highest baseline MAP.

Sixty-eight of 69 patients contributed data to the adjusted MAP analysis. There was no statistically significant difference in MAP at $3 \mathrm{~h}$ between the vasopressors, but patients who received norepinephrine had a nonsignificant, $5 \mathrm{~mm} \mathrm{Hg}$ higher adjusted MAP than patients who received phenylephrine $(\mathrm{p}=0.31)$ and dopamine $(\mathrm{p}=0.27)$ (fig. 2). Given discrepancies in time to vasopressor start and use of pentobarbital and hypertonic saline between the vasopressor groups, we performed a post hoc analysis to assess the influence of these potential con- 


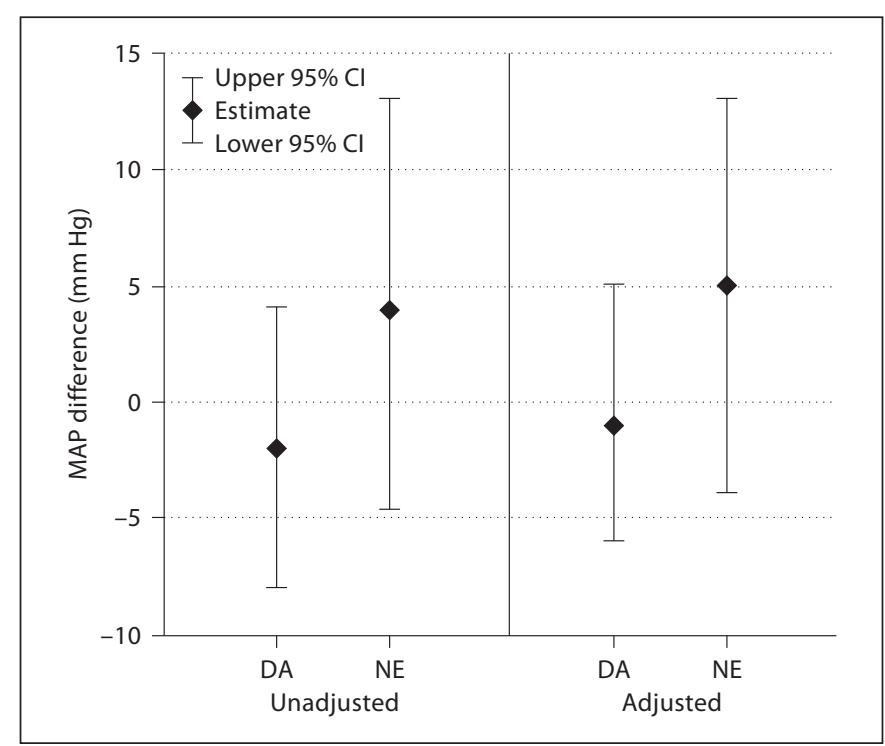

Fig. 2. Difference in MAP at $3 \mathrm{~h}$ compared with phenylephrine, using regression analysis. Estimates are from multivariate linear regression models assessing the difference in MAP at $3 \mathrm{~h}$ of therapy for dopamine (DA) and norepinephrine (NE) as compared to phenylephrine in patients receiving a single vasopressor. Baseline MAP is controlled for in both the unadjusted and adjusted models. The adjusted model additionally includes age, gender and ISS.

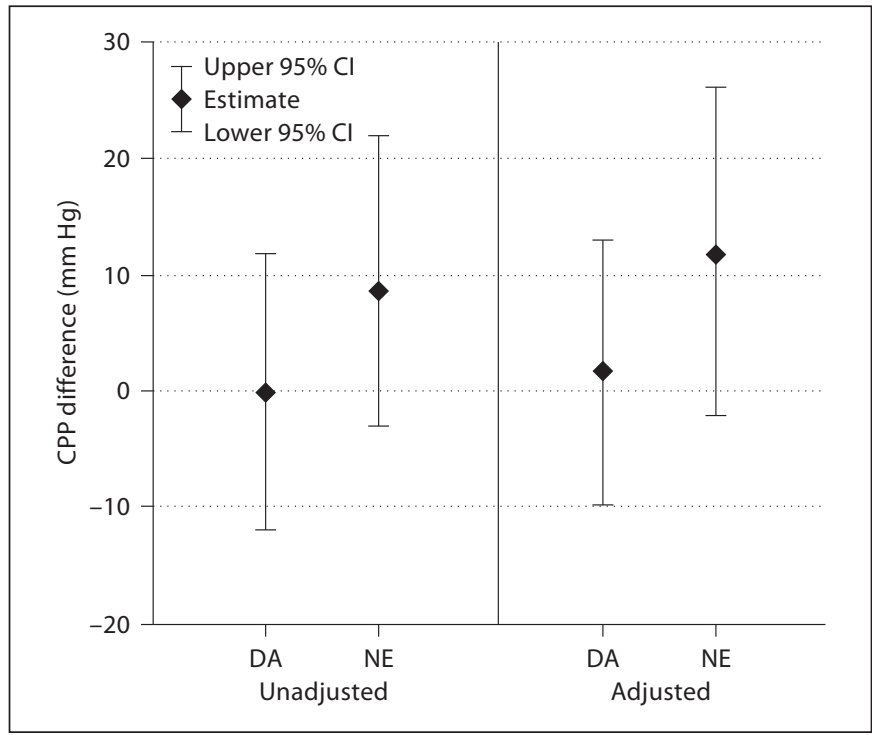

Fig. 3. Difference in CPP at $3 \mathrm{~h}$ compared with phenylephrine, using regression analysis. Estimates are from multivariate linear regression models assessing the difference in CPP at $3 \mathrm{~h}$ of therapy for dopamine (DA) and norepinephrine (NE) as compared to phenylephrine in patients receiving a single vasopressor. Baseline CPP is controlled for in both the unadjusted and adjusted models. The adjusted model additionally includes age, gender and ISS.

Table 1. Clinical characteristics by initial vasopressor (all patients, $\mathrm{n}=82$ )

\begin{tabular}{|c|c|c|c|c|}
\hline & $\begin{array}{l}\text { Phenylephrine } \\
(\mathrm{n}=47)\end{array}$ & $\begin{array}{l}\text { Dopamine } \\
(\mathrm{n}=24)\end{array}$ & $\begin{array}{l}\text { Norepinephrine } \\
(\mathrm{n}=8)\end{array}$ & $\begin{array}{l}\text { Epinephrine } \\
(\mathrm{n}=3)\end{array}$ \\
\hline Age $^{1}$, years & $13(1.1,17)$ & $7(0.1,17)$ & $15(2.9,17)$ & $1.9(0.3,16)$ \\
\hline Male & $68 \%$ & $79 \%$ & $88 \%$ & $33 \%$ \\
\hline Head AIS score ${ }^{2}$ & $5(5,5)$ & $5(4.5,5)$ & $5(5,5)$ & $5(3,5)$ \\
\hline ISS $^{2}$ & $34(25,43)$ & $29(25.5,46.5)$ & $50(32,57)$ & $35(9,43)$ \\
\hline GCS score at ICU admission ${ }^{2}$ & $5(3,6)$ & $3(3,5.5)$ & $6(3.5,7)$ & $3(3,3)$ \\
\hline Blood products ${ }^{2,3}, \mathrm{ml} / \mathrm{kg}$ & $7(0,25)$ & $8(0,20)$ & $0(0,0)$ & $80(9,244)$ \\
\hline Fluid balance $\mathrm{e}^{2,3}, \mathrm{ml} / \mathrm{kg}$ & $18(2,49)$ & $21(-30,59)$ & $18(10,55)$ & $210(52,308)$ \\
\hline LOS of survivors ${ }^{2}$, days & $18(11,24)$ & $10(4,20)$ & $28(16,41)$ & - \\
\hline Time to pressor start ${ }^{2,4}, \mathrm{~h}$ & $11(3,30)$ & $10(3,21)$ & $64(3.5,116.5)$ & $1(-1,2)$ \\
\hline In-hospital mortality & $35 \%$ & $46 \%$ & $25 \%$ & $100 \%$ \\
\hline Polytrauma & $55 \%$ & $42 \%$ & $88 \%$ & $33 \%$ \\
\hline Addition of 2 nd pressor ${ }^{5}$ & $9 \%$ & $21 \%$ & $13 \%$ & $100 \%$ \\
\hline Propofol $^{5}$ & $38 \%$ & $13 \%$ & $38 \%$ & - \\
\hline Hypertonic saline ${ }^{5}$ & $34 \%$ & $17 \%$ & $63 \%$ & - \\
\hline Mannitol $^{5}$ & $43 \%$ & $29 \%$ & $38 \%$ & $33 \%$ \\
\hline Furosemide ${ }^{5}$ & $4 \%$ & $4 \%$ & - & - \\
\hline Pentobarbital $^{5}$ & $2 \%$ & $8 \%$ & - & - \\
\hline Vasopressin for $\mathrm{DI}^{5}$ & - & $13 \%$ & - & - \\
\hline
\end{tabular}

DI $=$ Diabetes insipidus.

${ }^{1}$ Median (min., max.). ${ }^{2}$ Median (IQR). ${ }^{3}$ Over $12 \mathrm{~h}$ (6 h before and $6 \mathrm{~h}$ after start of first vasopressor). ${ }^{4}$ Time in hours to start of pressor after admission to ICU (negative values indicate start of medication prior to arrival in ICU, i.e. started in the emergency department). ${ }^{5}$ Administered anytime during the first $3 \mathrm{~h}$ after start of first vasopressor. 
Table 2. Clinical characteristics by single versus multiple vasopressors in the first $3 \mathrm{~h}$ after initiation of vasopressor $(\mathrm{n}=82)$

\begin{tabular}{|c|c|c|c|}
\hline & $\begin{array}{l}\text { Single pressor } \\
(\mathrm{n}=69)\end{array}$ & $\begin{array}{l}2+\text { pressors } \\
(\mathrm{n}=13)\end{array}$ & $\mathrm{p}$ \\
\hline Age $^{1}$, years & $13(0.1,17)$ & $14(0.3,17)$ & 0.828 \\
\hline Male & $71 \%$ & $77 \%$ & 1.0 \\
\hline Head AIS score ${ }^{2}$ & $5(5,5)$ & $5(5,5)$ & 0.834 \\
\hline ISS $^{2}$ & $34(26,43)$ & $26(25,43)$ & 0.330 \\
\hline GCS score at ICU & & & \\
\hline $\operatorname{admission}^{2}$ & $5(3,7)$ & $3(3,5)$ & 0.057 \\
\hline Blood products ${ }^{2,3}, \mathrm{ml} / \mathrm{kg}$ & $0(0,17)$ & $15(0,35)$ & 0.181 \\
\hline Fluid balance $\mathrm{e}^{2,3}, \mathrm{ml} / \mathrm{kg}$ & $18(-2,49)$ & $53(30,94)$ & 0.036 \\
\hline LOS in survivors ${ }^{2}$, days & $18(10,24)$ & $10(7,24)$ & 0.416 \\
\hline Time to pressor start ${ }^{2,4}, \mathrm{~h}$ & $12(3,41)$ & $3(1,9)$ & 0.006 \\
\hline In-hospital mortality & $32 \%$ & $77 \%$ & 0.004 \\
\hline Polytrauma & $54 \%$ & $54 \%$ & 1.0 \\
\hline Propofol $^{5}$ & $35 \%$ & $0 \%$ & 0.008 \\
\hline Hypertonic saline $e^{5}$ & $35 \%$ & $8 \%$ & 0.096 \\
\hline Mannitol $^{5}$ & $41 \%$ & $23 \%$ & 0.352 \\
\hline Furosemide ${ }^{5}$ & $4 \%$ & 0 & 1.0 \\
\hline Pentobarbital $^{5}$ & $4 \%$ & 0 & 1.0 \\
\hline
\end{tabular}

${ }^{1}$ Median (min., max.). ${ }^{2}$ Median (IQR). ${ }^{3}$ Over $12 \mathrm{~h}$ ( 6 h before and $6 \mathrm{~h}$ after start of first vasopressor). ${ }^{4}$ Time in hours to start of pressor after admission to ICU (negative values indicate start of medication prior to arrival in ICU, i.e. started in the emergency department). ${ }^{5}$ Administered anytime during the first $3 \mathrm{~h}$ after start of first vasopressor.

founders on our estimates. Adjusting additionally for these factors attenuated these estimates to the null, which was primarily related to time to vasopressor start and to a lesser extent to hypertonic saline, with no apparent effect of pentobarbital use.

Forty-seven patients contributed data to the adjusted $\mathrm{CPP}$ analysis. There was no statistically significant difference in CPP at $3 \mathrm{~h}$ between the vasopressor groups, but patients who received norepinephrine had a $12 \mathrm{~mm} \mathrm{Hg}$ higher CPP than phenylephrine $(\mathrm{p}=0.10)$ and a $10 \mathrm{~mm}$ $\mathrm{Hg}$ higher CPP than dopamine ( $\mathrm{p}=0.18)$ (fig. 3). Similar to the MAP analysis above, we performed a post hoc analysis to assess for confounding by time to vasopressor start and use of pentobarbital and hypertonic saline. Adding these factors to the regression model attenuated these estimates such that the norepinephrine group had an $8 \mathrm{~mm}$ $\mathrm{Hg}$ higher CPP than phenylephrine $(\mathrm{p}=0.39)$ and a $5 \mathrm{~mm}$ Hg higher CPP than dopamine ( $\mathrm{p}=0.59)$. This attenuation was due primarily to the effect of time to vasopressor start and use of hypertonic saline, and was not influenced by pentobarbital use.
Forty-seven patients contributed ICP data to the adjusted analysis. There was no statistically significant difference in ICP at $3 \mathrm{~h}$ between phenylephrine and dopamine (adjusted estimate of $3 \mathrm{~mm} \mathrm{Hg}$ lower in patients receiving dopamine; $\mathrm{p}=0.25$ ) or phenylephrine and norepinephrine (adjusted estimate of $5 \mathrm{~mm} \mathrm{Hg}$ lower in patients receiving norepinephrine; $\mathrm{p}=0.06$ ) in either the unadjusted or adjusted analyses. There was also no statistically significant difference between the norepinephrine and dopamine groups (with the norepinephrine group having an adjusted estimate of $2 \mathrm{~mm} \mathrm{Hg}$ lower than patients receiving dopamine; $\mathrm{p}=0.19$ ). Post hoc analysis adjusting for time to pressor start, hypertonic saline and pentobarbital altered the estimates such that norepinephrine had an $8 \mathrm{~mm} \mathrm{Hg}$ lower ICP than phenylephrine ( $\mathrm{p}=$ 0.13 ) and a $4 \mathrm{~mm} \mathrm{Hg}$ lower ICP than dopamine ( $\mathrm{p}=0.38)$.

In the adjusted analysis, heart rate was not statistically significantly different between the dopamine and phenylephrine groups. The norepinephrine group had a $14 \mathrm{bpm}$ lower heart rate compared to dopamine $(\mathrm{p}=0.05)$. There was no statistically significant difference in heart rate between the norepinephrine and phenylephrine groups (adjusted estimate of $9 \mathrm{bpm}$ lower in the norepinephrine group; $p=0.18$ ). Additionally, there were no statistically significant or clinically relevant differences in heart rate after post hoc analysis adjusting for time to pressor start, hypertonic saline and pentobarbital.

\section{Vasopressor Dose}

The median vasopressor dose received at $3 \mathrm{~h}$ was 0.5 $\mu \mathrm{g} / \mathrm{kg} / \mathrm{min}$ (IQR: $0.29,1.1$ ) for phenylephrine, $7 \mu \mathrm{g} / \mathrm{kg} /$ min (IQR: 5,15 ) for dopamine, and $0.05 \mu \mathrm{g} / \mathrm{kg} / \mathrm{min}$ (IQR: $0.04,0.08)$ for norepinephrine in patients receiving only a single agent during the first $3 \mathrm{~h}$. When restricted to those patients with available CPP data, the doses were similar.

\section{Age Effect}

Patients in the oldest age group ( $>14$ years) who received dopamine $(\mathrm{n}=5)$ and phenylephrine $(\mathrm{n}=21)$ had a higher increase in MAP (dopamine 38 vs. $20 \%$, and phenylephrine 20 vs. $14 \%)$ than the youngest group $(<5$ years) who received dopamine $(n=9)$ and phenylephrine $(\mathrm{n}=8)$, but this was not statistically significant. There was a similar increase in MAP for the youngest $(\mathrm{n}=2)$ and oldest $(n=5)$ patients who received norepinephrine by 27 and $26 \%$, respectively. 
Table 3. Clinical characteristics by initial vasopressor in patients receiving 1 vasopressor

\begin{tabular}{|c|c|c|c|c|c|c|}
\hline & \multicolumn{3}{|c|}{ Patients with MAP data $(n=69)$} & \multicolumn{3}{|c|}{ Patients with CPP data $(\mathrm{n}=48)$} \\
\hline & $\begin{array}{l}\text { phenylephrine } \\
(\mathrm{n}=43)\end{array}$ & $\begin{array}{l}\text { dopamine } \\
(\mathrm{n}=19)\end{array}$ & $\begin{array}{l}\text { norepinephrine } \\
(\mathrm{n}=7)\end{array}$ & $\begin{array}{l}\text { phenylephrine } \\
(\mathrm{n}=35)\end{array}$ & $\begin{array}{l}\text { dopamine } \\
(\mathrm{n}=8)\end{array}$ & $\begin{array}{l}\text { norepinephrine } \\
(\mathrm{n}=5)\end{array}$ \\
\hline Age $^{1}$, years & $13(1.1,17)$ & $7(0.1,17)$ & $15(2.9,17)$ & $13(1.1,17)$ & $6(2.4,17)$ & $15(2.9,17)$ \\
\hline Male & $67 \%$ & $74 \%$ & $86 \%$ & $69 \%$ & $88 \%$ & $80 \%$ \\
\hline Head AIS score ${ }^{2}$ & $5(5,5)$ & $5(4,5)$ & $5(5,5)$ & $5(4,5)$ & $5(4,5)$ & $5(5,5)$ \\
\hline admission $^{2}$ & $5(3,7)$ & $4(3,7)$ & $6(4,8)$ & $5(3,7)$ & $3.5(3,6)$ & $5(4,8)$ \\
\hline Blood products ${ }^{2,3}, \mathrm{ml} / \mathrm{kg}$ & $7(0,25)$ & $8(0,20)$ & $0(0,0)$ & $0(0,17)$ & $3(0,9)$ & $0(0,0)$ \\
\hline Fluid balance $\mathrm{e}^{2,3}, \mathrm{ml} / \mathrm{kg}$ & $18(2,49)$ & $18(-30,64)$ & $14(6,41)$ & $15(-2,44)$ & $-19(-34,7)$ & $14(6,14)$ \\
\hline LOS in survivors ${ }^{2}$, days & $18(13,25)$ & $13(3.5,20.5)$ & $28(16,41)$ & $17.5(11,24)$ & $20(6,21.5)$ & $25(15,47)$ \\
\hline Time to pressor start ${ }^{2,4}, \mathrm{~h}$ & $12(3,31)$ & $9(3,34)$ & $82(6,117)$ & $15(4,42)$ & $30.5(6,53.5)$ & $82(46,116)$ \\
\hline Thoracic $^{5}$ & $57 \%$ & $50 \%$ & $83 \%$ & $55 \%$ & $20 \%$ & $75 \%$ \\
\hline Multiple $^{5}$ & $52 \%$ & $50 \%$ & $100 \%$ & $50 \%$ & $40 \%$ & $100 \%$ \\
\hline Propofol $^{6}$ & $42 \%$ & $16 \%$ & $43 \%$ & $49 \%$ & $25 \%$ & $60 \%$ \\
\hline Hypertonic saline ${ }^{6}$ & $37 \%$ & $16 \%$ & $71 \%$ & $40 \%$ & $25 \%$ & $80 \%$ \\
\hline Mannitol $^{6}$ & $42 \%$ & $37 \%$ & $43 \%$ & $46 \%$ & $50 \%$ & $60 \%$ \\
\hline Furosemide $^{6}$ & $5 \%$ & $5 \%$ & - & $6 \%$ & - & - \\
\hline Pentobarbital $^{6}$ & $2 \%$ & $11 \%$ & - & $3 \%$ & $25 \%$ & - \\
\hline
\end{tabular}

${ }^{1}$ Median (min., max.). ${ }^{2}$ Median (IQR). ${ }^{3}$ Over $12 \mathrm{~h}$ (6 h before and $6 \mathrm{~h}$ after start of first vasopressor). ${ }^{4}$ Time in hours to start of pressor after admission to ICU (negative values indicate start of medication prior to arrival in ICU, i.e. started in the emergency department). ${ }^{5}$ Sites of extracranial trauma in the patients with polytrauma. ${ }^{6}$ Administered anytime during the first $3 \mathrm{~h}$ after start of first vasopressor.

Table 4. Median differences in vital signs at $3 \mathrm{~h}$ of therapy

\begin{tabular}{|c|c|c|c|c|}
\hline & Phenylephrine & Dopamine & Norepinephrine & $\mathrm{p}^{1}$ \\
\hline MAP $(n=69), m m ~ H g$ & $10(4,16)$ & $9(4,20)$ & $18(10,22)$ & 0.34 \\
\hline $\mathrm{CPP}(\mathrm{n}=48), \mathrm{mm} \mathrm{Hg}$ & $10(5,20)$ & $13.5(4.5,22.5)$ & $26(12,32)$ & 0.32 \\
\hline $\mathrm{ICP}(\mathrm{n}=48), \mathrm{mm} \mathrm{Hg}$ & $0(-7,6)$ & $-3.5(-6,-0.5)$ & $-2(-8,0)$ & 0.23 \\
\hline \multicolumn{5}{|l|}{ Heart rate $(\mathrm{n}=68)$, } \\
\hline bpm & $-4(-16,1)$ & $2(-7,15)$ & $-6(-20,1)$ & 0.09 \\
\hline
\end{tabular}

Median differences with IQR in parentheses in vital signs $3 \mathrm{~h}$ after initiation of vasoactive medication in patients treated with a single agent compared to baseline (only patients with baseline and 3-hour measurements are included for each parameter).

${ }^{1}$ Kruskal-Wallis equality-of-populations rank test. 
Comparison of Median before and after MAP with

Study Baseline and Endpoint Measurements

The minimum MAP during the hour prior to starting a vasopressor was lower than the median value over the $3 \mathrm{~h}$ prior to starting a vasopressor $(\mathrm{p}<0.001)$. However, the 3-hour MAP was not statistically significantly different from the median MAP during the $3 \mathrm{~h}$ after starting a vasopressor $(p=0.63)$.

\section{Discussion}

The main findings of this single-center study of pediatric moderate and severe TBI are the following: (1) while phenylephrine was used nearly twice as often as any other vasopressor overall, young children tended to receive dopamine and epinephrine, whereas older children received phenylephrine and norepinephrine; (2) blood pressure was most commonly managed utilizing a single drug during the first $3 \mathrm{~h}$ after the start of vasopressor therapy, and (3) while there was no statistically significant difference in MAP or CPP at $3 \mathrm{~h}$ after initiation of a vasopressor between vasopressor groups, patients who received norepinephrine had an adjusted $8 \mathrm{~mm} \mathrm{Hg}$ higher CPP than those who received phenylephrine, and an adjusted $5 \mathrm{~mm} \mathrm{Hg}$ higher CPP than those who received dopamine. Finally, patients who required a second vasopressor in the first $3 \mathrm{~h}$ of therapy were likely to have been more severely injured and critically ill based on the greater volume of blood products and fluid resuscitation they received, lower GCS score and higher in-hospital mortality. This is the first study to examine choice of vasopressor and to evaluate the association between drug choice and changes in blood pressure after pediatric TBI.

Vasopressors have different cardiovascular effects based on their profile for agonism of $\alpha$-adrenergic, $\beta$ adrenergic, dopamine or vasopressin receptors. Although this well-described profile characterizes the overall cardiovascular effect, there can be differential effects on various organ beds. In TBI, there are also the additional issues of potential loss of cerebral autoregulation and disruption of the integrity of the blood-brain barrier that could potentially affect the action of these vasopressors. Thus there have been studies investigating the effects of different vasopressors in TBI. While several studies compare vasopressors in animal models of TBI, the evidence as a whole is not conclusive [16-19]. However, 2 out of the 3 studies comparing dopamine and norepinephrine found that cerebral blood flow was better with norepinephrine $[17,18]$. There are 3 small ( $\mathrm{n}=19,11,10)$ human adult studies (prospective crossover trials) comparing the use of dopamine versus norepinephrine to augment CPP in adult TBI patients [2022]. In 1 study, ICP was higher with dopamine than norepinephrine for the same MAP [20]. However, Johnston et al. [21] showed that although there was no difference in ICP and cerebral oxygenation between dopamine and norepinephrine, dopamine had a more variable effect on arterial venous oxygen difference than norepinephrine. The third study showed no difference in mean ICP between dopamine and norepinephrine, yet reported that norepinephrine had predictable and significant increases in the mean flow velocity within the middle cerebral artery, whereas results with dopamine were variable and inconsistent [22]. These studies suggest that norepinephrine may be the preferred vasopressor to augment blood pressure after TBI. However, in this study, we did not find a statistically significant difference in hemodynamics between the vasopressors, although there was a trend for higher MAP and CPP with norepinephrine per our a priori analyses. In post hoc analyses, however, this trend for improved outcome in patients receiving norepinephrine appears to be partly due to the fact that a greater proportion of patients in this group received hypertonic saline, which has been shown to have a vasopressor effect [23-27], and to the longer time to vasopressor start.

After TBI, there is a complex cascade of events that occurs, leading to secondary brain injury, i.e. cerebral ischemia [28]. Whereas the primary insult cannot be reversed, the goal of treatment for clinicians is to limit secondary insults such as hypotension. Numerous studies have shown an association of systemic hypotension and/ or low CPP with poor outcomes in both adult and pediatric patients [3-12, 29-32]. Given this association, both pediatric and adult TBI guidelines recommend avoiding hypotension $[13,14]$. Additionally, the pediatric guidelines recommend maintaining CPP above $40 \mathrm{~mm} \mathrm{Hg}$ in children, noting though that an age-related continuum for the optimal CPP likely lies between 40 and $65 \mathrm{~mm} \mathrm{Hg}$ [13], and the adult guidelines recommend targeting a CPP of $50-70 \mathrm{~mm} \mathrm{Hg}$ [14]. However, there are no recommendations regarding the use of vasopressors to achieve these results. Based on the existing body of literature, norepinephrine may be the more reliable agent to achieve these goals in adults. While this current study did not find a statistically significant difference in MAP or CPP in children at $3 \mathrm{~h}$ of use, increases between 5 and $8 \mathrm{~mm} \mathrm{Hg}$ in CPP may be clinically relevant. 
Vasopressors can also have adverse effects such as reflexive bradycardia with the pure vasopressor phenylephrine, tachycardia with dopamine and epinephrine, and tissue ischemia with excessive vasoconstriction; the side effect profile varies by drug type. Some studies have found higher ICP with dopamine [20,33]. Given the retrospective nature of this study and low patient numbers, it was not possible to fully evaluate these side effects. However, heart rate and ICP were evaluated via regression analysis. Patients who received dopamine had a heart rate $14 \mathrm{bpm}$ higher than those receiving norepinephrine in our a priori analysis, although this difference was lost after post hoc adjustment for further confounders. Patients who received dopamine and norepinephrine had lower ICP than those receiving phenylephrine, although neither difference achieved statistical significance.

In this study, we assumed that $3 \mathrm{~h}$ was sufficient time for medications to be titrated to desired clinical effect, although we acknowledge that this is an extremely dynamic time in terms of the patients' physiology. Based on standard dose ranges for dopamine $(2-20 \mu \mathrm{g} / \mathrm{kg} / \mathrm{min})$ and norepinephrine $(0.05-2 \mu \mathrm{g} / \mathrm{kg} / \mathrm{min})$, the median doses at $3 \mathrm{~h}$ in those patients receiving monotherapy are relatively low, with a median dose of $7 \mu \mathrm{g} / \mathrm{kg} / \mathrm{min}$ for dopamine and $0.05 \mu \mathrm{g} / \mathrm{kg} / \mathrm{min}$ for norepinephrine. The median dose for phenylephrine was $0.5 \mu \mathrm{g} / \mathrm{kg} / \mathrm{min}$, which is the upper limit of the recommended dose range $(0.1-0.5 \mu \mathrm{g} / \mathrm{kg} / \mathrm{min})[34]$. One could argue that there may have been a higher 3-hour MAP with dopamine if the dose had been higher since at lower doses there are predominantly $\beta$-agonist effects, whereas at higher doses, $\alpha$-agonist effects predominate; however, the absence of information on how receptors vary by age and the retrospective nature of this study render this argument speculative. While there was a difference between the median and the lowest MAP prior to vasopressor start, we chose to examine change in hemodynamics using the lowest MAP since low values are typically what drive treatment with vasopressors. The lack of difference between the median MAP and 3-hour MAP values indicates that the increase in MAP was sustained over the $3 \mathrm{~h}$ after initiation of vasopressor therapy.

This study has some limitations. As this is a singlecenter study, it limits the generalizability of our results. The predominant use of phenylephrine in this study may not reflect nationwide practice, which may affect external validity. Given the retrospective nature of this study, there is a likelihood of indication bias regarding choice of first vasopressor, with more severely injured individuals systematically receiving one vasopressor over another. However, we attempted to account for this in our analysis by adjusting for ISS, although this possibly was not an adequate measure of injury severity, especially given that it did not seem to correlate with inhospital mortality or blood product and fluid resuscitation measurements. Vasopressor choice and titration was left to the discretion of the treating clinicians; however, there are no published data on this subject. Starting MAP and CPP in relation to goal MAP or CPP may have impacted outcomes; however, we were unable to capture this aspect, given that we had no uniform metric to use as some patients had a MAP goal, while others had only a CPP or systolic blood pressure target. We used a single blood pressure measurement at $3 \mathrm{~h}$ as the primary outcome measure, which does not reflect blood pressure throughout the duration of treatment. The time from admission to start of vasopressor was variable especially with regard to norepinephrine, which was started much later than the other agents, possibly indicating that there is something different about these patients or their pathophysiology as compared to the other groups; post hoc analyses controlling for this factor attenuated much of the difference in the MAP analysis but affected the CPP estimates to a lesser degree. Given the nonrandomized nature of our study, there are possibly other confounding factors that we were unable to assess - such as adequacy of shock resuscitation and occult cardiac dysfunction from thoracic trauma - that could have impacted our results. This study is small, especially the nonphenylephrine groups, which limits the power to detect differences between vasopressor groups. Lastly, in this study we evaluated MAP as our primary outcome measure and CPP as a secondary outcome measure to assess vasopressor effectiveness; however, given the complexities of the pathophysiology of brain trauma, it would likely be better to evaluate cerebral blood flow, cerebral metabolism, measures of cerebral oxygenation and, ultimately, neurologic outcomes. Despite these limitations, this study provides new information regarding vasopressor choice and associated changes in blood pressure and CPP in children with TBI. Prospective, multicenter studies describing the frequency and diversity in vasopressor use as well as randomized trials comparing the effect of vasopressor use on short- and long-term outcomes are likely to overcome these limitations and provide comparative data that can justify clinical practice in this area.

In summary, monotherapy with phenylephrine was used more frequently to augment blood pressure for this 
cohort of patients, but vasopressor choice varied by age. Overall, while there was no statistically significant difference in MAP or CPP between vasopressor groups, norepinephrine was associated with a clinically relevant higher CPP and lower ICP at $3 \mathrm{~h}$ after start of vasopressor therapy compared to the other vasopressors examined. Future studies are needed to examine differences in vasopressor effects and optimal vasopressor choice for children requiring blood pressure support after pediatric TBI.

\section{Acknowledgments}

We gratefully acknowledge Sandra Burkhart, and the financial support from the Lyford Family Endowment for Intensive Care (J.L.D.G.) and the NIH (K23; M.S.V.) for this project.

\section{References}

110 leading causes of death, United States, 10 Elias-Jones AC, Punt JA, Turnbull AE, Jas2005, all races, both sexes. http://www.cdc. gov/ncipc/wisqars/ (accessed September 30, 2008).

$>2$ Rutland-Brown W, Langlois JA, Thomas KE, $\mathrm{Xi}$ YL: Incidence of traumatic brain injury in the United States, 2003. J Head Trauma Rehabil 2006;21:544-548.

-3 Andrews PJ, Sleeman DH, Statham PF, McQuatt A, Corruble V, Jones PA, Howells TP, Macmillan CS: Predicting recovery in patients suffering from traumatic brain injury by using admission variables and physiologic data: a comparison between decision tree analysis and logistic regression. J Neurosurg 2002;97:326-336.

4 Carter BG, Butt W, Taylor A: ICP and CPP: excellent predictors of long-term outcome in severely brain-injured children. Childs Nerv Syst 2008;24:245-251.

5 Català-Temprano A, Claret Teruel G, Cambra Lasaosa FJ, Pons Odena M, Noguera Julián A, Palomeque Rico A: Intracranial pressure and cerebral perfusion pressure as risk factors in children with traumatic brain injury. J Neurosurg 2007;106(6 suppl):463-466.

$\checkmark 6$ Chamber IR, Jones PA, Lo TYM, Forsyth RJ, Fulton B, Andrews PJD, Mendelow AD, Minns RA: Critical thresholds of intracranial pressure and cerebral perfusion pressure related to age in pediatric head injury. J Neurol Neurosurg Psychiatry 2006;77:234-240.

$>7$ Changaris DG, McGraw CP, Richardson JD, Garretson HD, Arpin EJ, Shields CB: Correlation of cerebral perfusion pressure and Glasgow Coma Scale to outcome. J Trauma 1987;27:1007-1013.

$>8$ Clifton GL, Miller ER, Choi SC, Levin HS: Fluid thresholds and outcome from severe brain injury. Crit Care Med 2002;30:739745.

$>9$ Downard C, Hulka F, Mullins RJ, Piatt J, Chesnut R, Quint P, Mann NC: Relationship of cerebral perfusion pressure and survival in pediatric brain-injured patients. J Trauma 2000;49:654-658. pan T: Management and outcome of severe head injuries in the Trent region 1985-1990. Arch Dis Child 1992;67:1430-1435.

1 Hackbarth RM, Rzeszutko KM, Sturm G, Donders J, Kuldanek AS, Sanfilippo DJ: Survival and functional outcome in traumatic brain injury: a retrospective review and analysis of predictive factors. Crit Care Med 2002;30:1630-1635.

12 Kaiser G, Pfenninger J: Effect of neurointensive care upon outcome following severe head injuries in childhood: a preliminary report. Neuropediatrics 1984;15:68-75.

13 Adelson PD, Bratton SL, Carney NA, Chesnut RM, du Coudray HE, Goldstein B, Kochanek PM, Miller HC, Partington MD, Selden NR, Warden CR, Wright DW, American Association for Surgery of Trauma, Child Neurology Society, International Society for Pediatric Neurosurgery, International Trauma Anesthesia and Critical Care Society, Society of Critical Care Medicine, World Federation of Pediatric Intensive and Critical Care Societies: Guidelines for the acute medical management of severe traumatic brain injury in infants, children, and adolescents. Pediatr Crit Care Med 2003;4(3

14 Bratton SL, Chestnut RM, Ghajar J, McConnell Hammond FF, Harris OA, Hartl R, Manley GT, Nemecek A, Newell DW, Rosenthal G, Schouten J, Shutter L, Timmons SD, Ullman JS, Videtta W, Wilberger JE, Wright DW, Brain Trauma Foundation, American Association of Neurological Surgeons, Congress of Neurological Surgeons, Joint Section on Neurotrauma and Critical Care, AANS/ CNS: Guidelines for the management of severe traumatic brain injury. J Neurotrauma 2007;24(suppl 1):S7-S13, S59-S64.

15 Chaiwat O, Sharma D, Udomphorn Y, Armstead WM, Vavilala MS: Cerebral hemodynamic predictors of poor 6-month Glasgow Outcome Score in severe pediatric traumatic brain injury. J Neurotrauma 2009;26:657663. suppl):S12-S18, S31-S33.
6 Dudkiewicz M, Proctor KG: Tissue oxygenation during management of cerebral perfusion pressure with phenylephrine or vasopressin. Crit Care Med 2008;36:1-10.

17 Kroppenstedt SN, Sakowitz OW, Thomale UW, Unterberg AW, Stover JF: Influence of norepinephrine and dopamine on cortical perfusion, EEG activity, extracellular glutamate, and brain edema in rats after controlled cortical impact injury. J Neurotrauma 2002; 19:1421-1432.

18 Kroppenstedt SN, Sakowitz OW, Thomale UW, Unterberg AW, Stover JF: Norepinephrine is superior to dopamine in increasing cortical perfusion following controlled cortical impact injury in rats. Acta Neurochir Suppl 2002;81:225-227.

19 Ract C, Vigué B, Bodjarian N, Mazoit JX, Samii K, Tadié M: Comparison of dopamine and norepinephrine after traumatic brain injury and hypoxic-hypotensive insult. J Neurotrauma 2001;18:1247-1254.

20 Ract C, Vigué B: Comparison of the cerebral effects of dopamine and norepinephrine in severely head-injured patients. Intensive Care Med 2001;27:101-106.

21 Johnston AJ, Steiner LA, Chatfield DA, Coles JP, Hutchinson PJ, Al-Rawi PG, Menon DK, Gupta AK: Effect of cerebral perfusion pressure augmentation with dopamine and norepinephrine on global and focal brain oxygenation after traumatic brain injury. Intensive Care Med 2004;30:791-797.

22 Steiner LA, Johnston AJ, Czosnyka M, Chatfield DA, Salvador R, Coles JP, Gupta AK, Pickard JD, Menon DK: Direct comparison of cerebrovascular effects of norepinephrine and dopamine in head-injured patients. Crit Care Med 2004;32:1049-1054.

23 Antunes VR, Yao ST, Pickering AE, Murphy D, Paton JF: A spinal vasopressinergic mechanism mediates hyperosmolarity-induced sympathoexcitation. J Physiol 2006;576: 569-583. 
24 Batista MB, Bravin AC, Lopes LM, Gerenuti E, Elias LL, Antunes-Rodrigues J, GiustiPaiva A: Pressor response to fluid resuscitation in endotoxic shock: involvement of vasopressin. Crit Care Med 2009;37:2968-2972.

25 Farquhar WB, Paul EE, Prettyman AV, Stillabower ME: Blood pressure and hemodynamic response to an acute sodium load in humans. J Appl Physiol 2005;99:1545-1551.

26 de Almeida Costa EF, Pedrino GR, Lopes OU, Cravo SL: Afferent pathways involved in cardiovascular adjustments induced by hypertonic saline resuscitation in rats submitted to hemorrhagic shock. Shock 2009;32: 190-193.

-27 Giusti-Paiva A, Martinez MR, Bispo-da-Silva $L B$, Salgado MC, Elias LL, Antunes-Rodrigues J: Vasopressin mediates the pressor effect of hypertonic saline solution in endotoxic shock. Shock 2007;27:416-421.
28 Werner C, Engelhard K: Pathophysiology of traumatic brain injury. Br J Anaesth 2007;99: $4-9$.

29 Chesnut RM, Marshall LF, Klauber MR, Blunt BA, Baldwin N, Eisenberg HM, Jane JA, Marmarou A, Foulkes MA: The role of secondary brain injury in determining outcome from severe head injury. J Trauma 1993;34:216-222.

30 Chesnut RM, Marshall SB, Piek J, Blunt BA, Klauber MR, Marshall LF: Early and late systemic hypotension as a frequent and fundamental source of cerebral ischemia following severe brain injury in the Traumatic Coma Data Bank. Acta Neurochir Suppl (Wien) 1993;59:121-125.
1 Kokoska ER, Smith GS, Pittman T, Weber TR: Early hypotension worsens neurological outcome in pediatric patients with moderately severe head trauma. J Pediatr Surg 1998; 33:333-338.

32 Vavilala MS, Bowen A, Lam AM, Uffman JC, Powell J, Winn HR, Rivara FP: Blood pressure and outcome after severe pediatric traumatic brain injury. J Trauma 2003;55:10391044.

33 Myburgh JA, Upton RN, Grant C, Martinez A: A comparison of the effects of norepinephrine, epinephrine and dopamine on cerebral blood flow and oxygen utilization. Acta Neurochir Suppl (Wien) 1998;71:19-21.

34 Lee C, Custer JW, Rau, RE: Drug doses; in Custer JW, Rau RE (eds): The Harriet Lane Handbook, ed 18. Philadelphia, Elsevier, 2009, pp 697-1029. 